\title{
A Financial Model for Team-Based Opioid Use Disorder Treatment
}

\author{
Mackenzie Farrar, PharmD, Zach White, LCSW, LCAS, Stephen Hulkower, MD, \\ E. Blake Fagan, MD, and Courtenay Gilmore Wilson, PharmD, BCACP, CPP
}

Introduction: Opioid use disorder (OUD) affects 2 million Americans, yet many patients do not receive treatment. Lack of team-based care is a common barrier for office-based opioid treatment (OBOT). In 2015, we started OBOT in a family medicine practice. Based on our experiences, we developed a financial model for hiring a team member to provide nonbillable OBOT services through revenue from increased patient volume.

Methods: We completed a retrospective chart review from July 2015 to December 2016 to determine the average difference in medical visits per patient per month pre-OBOT versus post-OBOT. Secondary outcomes were the percentage of visits coded as a Level 3, Level 4, and Level 5, and the percentage of patients with Medicaid, private insurance, or self pay. With this information, we extrapolated to build a financial model to hire a team member to support OBOT.

Results: Twenty-three patients received OBOT during the study period. There was a net increase of 1.93 visits per patient per month $(P<.001)$. Fourteen patients were insured by Medicaid, 7 had private insurance, and 2 were self pay. Twenty-three percent of OBOT visits were Level 3, 69\% were Level 4, and $8 \%$ were Level 5 . Assuming all visits were reimbursed by Medicaid and accounting for $20 \%$ cost of business, treating 1 existing patient for 1 year would generate \$1,439. Treating 1 new patient would generate $\$ 1,677$.

Conclusions: In a fee-for-service model, the revenue generated from increased medical visits can offset the cost of hiring a team member to support nonbillable OBOT services. (J Am Board Fam Med 2020;33:124-128.)

Keywords: Buprenorphine, Fee-for-Service Plans, Medicaid, Opioid-Related Disorders, Opioids, Retrospective Studies

Opioid use disorder (OUD) is a chronic, relapsing, treatable brain disease that affects millions of Americans. ${ }^{1}$ In recent years, the rise in incidence of

This article was externally peer reviewed.

Submitted 26 June 2019; revised 26 September 2019; accepted 29 September 2019.

From the Mountain Area Health Education Center (MAHEC), Asheville, NC (MF, ZW, SH); University of North Carolina (UNC) School of Medicine Chapel Hill, NC (SH, EBF, CGW); Centers for Disease Control and Prevention Foundation, Atlanta, GA (EBF); UNC Health Sciences at MAHEC Asheville, NC (EBF, CGW); UNC Eshelman School of Pharmacy, Chapel Hill, NC (CGW).

Funding: This publication is supported by the Health Resources and Services Administration (HRSA) of the U.S. Department of Health and Human Services (HHS) as part of an award totaling \$1,656,886 with $0 \%$ financed with non-governmental sources. The contents are those of the authors and do not necessarily represent the official views of nor an endorsement, by HRSA, HHS, or the U.S. Government. For more information, please visit HRSA.gov.

Conflict of interest: none declared.
Hepatitis C, increase in emergency department and hospitalization utilization, and decrease in Americans' life expectancy have been attributed to untreated OUD. ${ }^{2}$ The White House Council of Economic Advisors estimated the societal cost of opioid misuse and use disorder to be $\$ 504$ billion. ${ }^{3}$ Methadone, buprenorphine, and naltrexone are recommended by Substance Abuse and Mental Health Services Administration (SAMHSA), American Society of Addiction Medicine (ASAM), and National Institute on Drug Abuse as the standard for treatment. ${ }^{4-6}$ Medications for OUD have been shown to reduce fatal overdoses, improve retention in treatment, lower transmission rates of HIV infec-

Corresponding author: Courtenay Gilmore Wilson, PharmD, BCACP, CPP, 123 Hendersonville Rd, Asheville, NC 28803 (E-mail: Courtenay.wilson@mahec.net). 
tions, reduce criminal activity, and improve social functioning. ${ }^{2}$ Despite the profound consequences of this disease, these medications remain highly underutilized. ${ }^{1}$

Office-based opioid treatment (OBOT) is the provision of treatment for OUD within the general medical setting with buprenorphine or naltrexone. ${ }^{4-6}$ When providing OBOT, ASAM and SAMHSA recommend weekly to no-less-than monthly office visits. $^{4-5}$ To prescribe buprenorphine, federal regulations require qualifying providers to complete additional training and receive a waiver. ${ }^{4}$ In 2019, only 72,696 providers are waivered to prescribe buprenorphine. ${ }^{7}$ Less than $30 \%$ of waivered providers use their waiver. ${ }^{8}$ Per federal law, methadone is restricted to opioid treatment programs, thus is not available in primary care. ${ }^{4}$

Family medicine providers are well poised to fill this treatment gap, yet many barriers to implementing OBOT in primary care exist. These include inadequately trained staff, insufficient time, inadequate office space, prescribing regulations, and lack of available mental health or psychosocial support services. ${ }^{9}$ To address these barriers, many successful OBOT services use a collaborative care model where a variety of disciplines provides teambased care. ${ }^{10}$ However, financial concerns may hinder the ability to implement a collaborative care model. ${ }^{11}$ The purpose of this study was 2 -fold. First, we sought to determine the impact of offering OBOT services on the frequency with which we saw established patients. Second, we sought to develop a financial model for hiring a team member to support nonbillable OBOT services based on the increased patient volume.

\section{Methods \\ Setting}

We are a community-based, family medicine residency with integrated behavioral medicine and clinical pharmacy. With 1 hub and 6 regional clinics, we serve over 33,000 patients in rural and urban communities in Appalachia. In July 2015, a faculty family medicine physician, nurse practitioner, and clinical pharmacist began providing OBOT at the main location. ${ }^{12}$ For the first year, to gain clinical experience, we limited eligibility to established patients for at least 1 year and those maintained on a buprenorphine-containing medication. Five faculty physicians were waivered to prescribe buprenor- phine. The nurse practitioner or clinical pharmacist completed intake visits. Per the ASAM and SAMHSA recommendations, the physician saw the patient no less than monthly. ${ }^{4-5}$ In congruence with these guidelines, OUD is not subject to the North Carolina Medicaid annual visit limitation. ${ }^{13}$ Visits were billed based on time or complexity using the evaluation and management services. Beginning in June 2016, we started inductions onto buprenorphine, opened access to new patients, offered OBOT at all locations, and waivered additional faculty and residents.

\section{Data Collection}

We completed a retrospective chart review from July 2015 to December 2016 to determine the number of medical visits per patient per month in the year before receiving OBOT (pre-OBOT) compared with the number of medical visits per patient per month since receiving OBOT (postOBOT). Patients were included if they received at least 1 prescription for a buprenorphine-containing medication during the study period. Each patient's chart was reviewed from 1 year before the first prescription through the end of the study period. Information about the level of visit billed and insurance type were collected from the practice's revenue cycle management database. This study was reviewed by our local institutional review board and deemed not to be human subject research.

\section{Data Analysis}

For our first objective, the primary outcome was the average difference in medical visits per patient per month pre-OBOT to post-OBOT with a 2-tailed paired $t$-test to determine significance. Secondary outcomes were the percentage of visits coded as a Level 3, Level 4, and Level 5 and the percentage of patients with Medicaid, private insurance, or self pay. These outcomes were summarized using descriptive data. For our second objective, the primary outcome data were applied to determine the number of patients needed in OBOT to justify hiring a team member to provide nonbillable services. We used the North Carolina Medicaid Physician Fee Schedule to determine the nonfacility fee reimbursement rate. ${ }^{14} \mathrm{We}$ accounted for a $20 \%$ reduction for cost of business, which includes central business office, provider, facilities, and staffing costs. We utilized the number of work relative value units to estimate the portion of a full-time 
Table 1. Potential Annual Revenue for Providing Office-Based Opioid Treatment to New Patients

\begin{tabular}{lcccc}
\hline Patients, n & $\begin{array}{c}\text { Level 3 Visits } \\
\text { per Year, n }\end{array}$ & $\begin{array}{c}\text { Level 4 Visits } \\
\text { per Year, n }\end{array}$ & $\begin{array}{c}\text { Level 5 Visits } \\
\text { per Year, n }\end{array}$ & $\begin{array}{c}\text { Potential Annual } \\
\text { Revenue, } \$^{*}\end{array}$ \\
\hline 25 & 155 & 467 & 53 & $41,928.28$ \\
50 & 311 & 933 & 105 & $83,856.56$ \\
75 & 466 & 1400 & 158 & $125,784.84$ \\
100 & 621 & 1867 & 211 & $167,713.12$ \\
150 & 932 & 2800 & 316 & $251,569.68$ \\
200 & 1242 & 3734 & 422 & $335,426.24$ \\
\hline
\end{tabular}

*Includes 20\% reduction for cost of business.

equivalent family medicine physician required to treat the OBOT panel. ${ }^{15-16}$

\section{Results}

During the study period, 23 patients received OBOT. Pre-OBOT, patients had an average of 0.32 medical visits per month (range, 0.00 to 1.17). Post-OBOT, patients had an average of 2.25 medical visits per month (range, 0.75 to 5.00). The average difference was a net increase of 1.93 medical visits per patient per month $(P<$ $.001)$. The average time post-OBOT was 4.61 months (range, 1 to 16). The total person-time of followup was 106.03 person-months. Fourteen patients were insured by Medicaid, 7 had private insurance, and 2 were self pay. Post-OBOT visits were $23.05 \%$ for Level 3, 69.14\% for Level 4, and $7.81 \%$ for Level 5 .

Based on these findings, we developed a financial model for new (Table 1) and current (Table 2) patients assuming all medical visits were reimbursed by North Carolina Medicaid with a $20 \%$ reduction for cost of business. Treating 1 existing patient for 1 year would generate $\$ 1,438.61$. Treating 1 new patient for 1 year would generate $\$ 1,677.13$. An OBOT panel of 100 existing patients would require 0.7 full-time equivalents of a family medicine physician (Table 3 ).

\section{Discussion}

The American Medical Association Opioid Task Force calls physicians to close the treatment gap for patients with OUD. ${ }^{17}$ Family medicine practices should expand access to evidence-based, standardof-care treatment for OUD. This financial model justifies a collaborative care model for providing the nonbillable services associated with treating OUD.

The unique needs and characteristics of a practice will undoubtedly guide which team member is most needed. Licensed clinical addiction specialists (LCAS) are utilized in primary care clinics as behavioral health specialists, care managers, and community engagement specialists. ${ }^{18}$ In Vermont's Hub-and-Spoke Model, nurses are responsible for coordination of care for patients transferring between Opioid Treatment Programs and primary care OBOT. ${ }^{19}$ Pharmacists provide education, manage medications through drug therapy management protocols, and ensure medication access. ${ }^{20}$ In our institution, this financial model has created positions for 2 LCASs and 1 peer support specialist.

Table 2. Potential Annual Revenue for Providing Office-Based Opioid Treatment to Current Patients

\begin{tabular}{lcccc}
\hline Patients, n & $\begin{array}{c}\text { Level 3 Visits } \\
\text { per Year, n }\end{array}$ & $\begin{array}{c}\text { Level 4 Visits } \\
\text { per Year, n }\end{array}$ & $\begin{array}{c}\text { Level 5 Visits } \\
\text { per Year, n }\end{array}$ & $\begin{array}{c}\text { Potential Annual } \\
\text { Revenue, } \$^{*}\end{array}$ \\
\hline 25 & 133 & 400 & 45 & $35,965.15$ \\
50 & 266 & 801 & 90 & $71,930.29$ \\
75 & 400 & 1201 & 136 & $107,895.44$ \\
100 & 533 & 1601 & 181 & $143,860.59$ \\
150 & 799 & 2402 & 271 & $215,790.88$ \\
200 & 1065 & 3203 & 362 & $287,721.17$ \\
\hline
\end{tabular}

${ }^{*}$ Includes $20 \%$ reduction for cost of business. 
Table 3. Full-Time Equivalent of a Family Medicine Physician Needed for Office-Based Opioid Treatment

\begin{tabular}{lcc}
\hline Patients, $n$ & Total wRVU per Year & FTE Required \\
\hline 25 & 962.2 & 0.2 \\
50 & 1924.4 & 0.3 \\
75 & 2886.6 & 0.5 \\
100 & 3848.8 & 0.7 \\
150 & 5773.2 & 1.0 \\
200 & 7697.6 & 1.3 \\
\hline
\end{tabular}

FTE, full-time equivalent; wRVU, work relative value unit.

The responsibilities of these positions vary by role and include providing behavioral health services to patients, ensuring we meet state and federal regulations, licensing new providers, screening new patients, educating and training staff, coordinating patient care, and collaborating with outside stakeholders.

This financial model relies solely on a fee-forservice payment structure, as value-based models for OUD are not well established. In 2019, none of the quality measures recognized by the Medicare Shared Savings Program for Accountable Care Organizations address substance use disorders (SUDs). ${ }^{21} \mathrm{Na}$ tional organizations are working to expand value-based payment options for SUDs. The National Committee for Quality Assurance created initiatives for the Health care Effectiveness Data and Information Set (HEDIS) to improve follow up after an SUD-related emergency department visit. ${ }^{22}$ HEDIS implemented the Initiation and Engagement of Alcohol and Other Drug Dependence Treatment, which proposes that treatment should be started within 14 days of diagnosis and engagement with 2 or more additional services should occur within 30 days of the initial visit. ${ }^{22}$ The National Quality Forum has implemented a measure for the continuity of pharmacotherapy for OUD for 180 days for hospitals providing OBOT services in the outpatient setting. ${ }^{23}$ The Centers for Disease Control and Prevention developed clinical quality improvement measures ensuring patients with OUD are referred to or prescribed medications for OUD. ${ }^{24}$

\section{Limitations}

There are limitations to this financial model that one must consider before implementation. This financial model assumes the clinic has the capacity to accommodate the projected increase in patient volume. Furthermore, the financial model did not account for any direct billing opportunities afforded to the new team member, which could aid in financially sustaining the position. In addition, the financial model does not account for reimbursement from private insurance companies, which is often higher than Medicaid reimbursement; therefore, this may be a conservative estimate of revenue. For the new patient model, we did not account for the 1 time initial new patient visit as it is reimbursed only slightly higher than the established patient visit at the same level. ${ }^{14}$

\section{Conclusions}

Family medicine practices use the revenue generated from increased medical visits to support collaborative care models to provide nonbillable services related to OBOT.

To see this article online, please go to: bttp://jabfm.org/content/ 33/1/124.full.

\section{References}

1. Substance Abuse and Mental Health Services Administration. Key substance use and mental health indicators in the United States: Results from the 2018 National Survey on Drug Use and Health (HHS Publication No. PEP19-5068, NSDUH Series H-54). Rockville, MD: Center for Behavioral Health Statistics and Quality, Substance Abuse and Mental Health Services Administration; 2019. Available from: https://www.samhsa.gov/data/.

2. National Academies of Sciences, Engineering, and Medicine. Medications for Opioid Use Disorder Save Lives. Washington, DC: The National Academies Press; 2019.

3. The Council of Economic Advisors. The underestimated costs of the opioid crisis. November 2017. Available from: https://www.whitehouse.gov/sites/whitehouse.gov/files/images/The $\% 20$ Underestimated $\%$ 20Cost $\%$ 20of\%20the\%20Opioid\%20Crisis.pdf. Accessed May 17, 2019.

4. Substance Abuse and Mental Health Services Administration. Medications for Opioid Use Disorder. Treatment Improvement Protocol (TIP) Series 63, Full Document. HHS Publication No. (SMA) 185063FULLDOC. Rockville, MD: Substance Abuse and Mental Health Services Administration; 2018.

5. Kampman K, Jarvis M. The ASAM National Practice Guideline for the Use of Medications in the Treatment of Addiction Involving Opioid Use, J Addict Med 2015;9:358-67. 
6. National Institute on Drug Abuse. Medications to Treat Opioid Use Disorder. Rockville, MD: National Institute on Drug Abuse, 2018.

7. Substance Abuse and Mental Health Services Administration. Practitioner and Program Data. Available from: https://www.samhsa.gov/medication-assistedtreatment/training-materials-resources/practitionerprogram-data. Accessed September 10, 2019.

8. Moran GE, Snyder CM, Noftsinger RF, et al. Implementing medication-assisted treatment for opioid use disorder in rural primary care: environmental scan, volume 1. Rockville, MD: Agency for Healthcare Research and Quality; October 2017.

9. Deflavio JR, Rolin SA, Nordstrom BR, Kazal LA. Analysis of barriers to adoption of buprenorphine maintenance therapy by family physicians. Rural and Remote Health 2015;15:3019.

10. Alford DP, LaBelle CT, Kretsch N, et al. Collaborative care of opioid-addicted patients in primary care using buprenorphine: five-year experience. Arch Intern Med 2011;171:425-31.

11. Andrilla CH, Coulthard C, Larson E. Barriers rural physicians face prescribing buprenorphine for opioid use disorder. Ann Fam Med 2017;15:359-62.

12. Wilson CG, Fagan EB. Providing office-based treatment of opioid use disorder. Ann Fam Med 2017;15: 481.

13. North Carolina Department of Health and Human Services. Annual Visit. Available from: https:// medicaid.ncdhhs.gov/providers/programs-services/ annual-visit. Accessed September 12, 2019.

14. North Carolina Department of Health and Human Services. Physician fee schedule. Available from: https://files.nc.gov/ncdma/documents/Fee-Schedules/ Physician-Services-Fee-Schedule20190607.pdf. Accessed June 13, 2019.

15. Centers for Medicare and Medicaid Services. Physician fee schedule. Available from: www.cms.gov/ apps/physician-fee-schedule/search/search-criteria. aspx. Accessed September 26, 2019.
16. 2019 MGMA DataDive Provider Compensation, based on 2018 data. 2019. Used with permission from MGMA, 104 Inverness Terrace East, Englewood, Colorado 80112. 877.275.6462. Available from: www.mgma.com.

17. American Medical Association Opioid Task Force. 2019 Progress Report. Available from: https:// www.ama-assn.org/system/files/2019-06/opioidtask-force-progress-report.pdf. Accessed June 13, 2019.

18. Chou R. et al. Medication-assisted treatment models of care for opioid use disorder in primary care settings. Rockville, MD: Agency for Healthcare Research and Quality; 2016.

19. Korthuis PT, McCarty D, Weimer M, et al. Primary care-based models for the treatment of opioid use disorder. Ann Intern Med 2017;166:268-279.

20. DiPaula BA, Menachery E. Physician-pharmacist collaborative care model for buprenorphine-maintained- opioid-dependent patients. J Amer Pharm Assoc 2015;55:187-92.

21. Medicare Shared Savings Program. Quality measure benchmarks for the 2018 and 2019 reporting years. Guidance document. February 2019. Version \#2. Available from: https://www.cms.gov/Medicare/ Medicare-Fee-for-Service-Payment/sharedsavingsprogram/Downloads/2018-and-2019-qualitybenchmarks-guidance.pdf. Accessed June 13, 2019.

22. National Committee for Quality Assurance. HEDIS Measures. Washington, DC: National Committee for Quality Improvement; 2019.

23. National Qualified Forum. National qualified forum measures 2019. Available from: www.qualityforum. org. Accessed April 30, 2019.

24. Centers for Disease Control and Prevention. Quality improvement and care coordination: implementing the CDC guideline for prescribing opioids for chronic pain. Available from: https://www.cdc.gov/ drugoverdose/pdf/prescribing/CDC-DUIP-QualityImprovementAndCareCoordination-508.pdf. Accessed June 13, 2019. 